Species Diversity, 2005, 10, 125-133

\title{
Two New Species of the Flower Bug Genus Scoloposcelis (Insecta: Heteroptera: Anthocoridae) from Japan
}

\author{
Kazutaka Yamada and Toshiya Hirowatari \\ Entomological Laboratory, Graduate School of Agriculture and Biological Sciences, \\ Osaka Prefecture University, Gakuen-cho 1-1, Sakai, Osaka, 599-8531 Japan \\ E-mail: kazu2000@plant.osakafu-u.ac.jp (KY)
}

(Received 28 July 2004; Accepted 6 January 2005)

\begin{abstract}
Two species of lyctocorine flower bug that inhabit subtropical islands of Japan are described as new: Scoloposcelis albodecussata sp. nov., from the Ryukyus, and $S$. boninensis sp. nov., from the Ogasawaras (Bonin Islands). A key is presented to distinguish the four species of Scoloposcelis known to occur in Japan.
\end{abstract}

Key Words: Heteroptera, Anthocoridae, Lyctocorinae, Scoloposcelis, new species, Japan.

\section{Introduction}

Scoloposcelis Fieber, 1864 is a small genus of flower bugs in the subfamily Lyctocorinae. Its 10 species are distributed over the Old and New World tropics, subtropics, and temperate zone. They are predators of bark beetles and other tiny arthropods that occur under the bark of conifers or deciduous trees (cf., Carayon 1954a, 1956; Muraleedharan and Ananthakrishnan 1974; Péricart 1996).

This genus is characterized by the body being elongate, flattened, and parallelsided; the femur usually being spinulate on the ventral surface; and the uradenia having an ampulla, a unique glandular opening on the male abdominal sternum IV (Carayon 1954b).

Yasunaga (2001) recorded Scoloposcelis pulchella (Zetterstedt, 1838) and S. parallela (Motschulsky, 1863) from Hokkaido and the Ryukyus, respectively. The latter is known to occur also in Micronesia (southern Marianas and Palau), where it was collected under dead bark (Herring 1967), but no species of the genus has been known from the Ogasawara Islands north of Micronesia. In our recent investigations, two other species were found in the subtropical regions of Japan, one from the Ryukyus and the other from the Ogasawara Islands. These species are similar to S. parallela and S. asiaticus Muraleedharan and Ananthakrishnan, 1974, but distinct as described below. A key is presented for the separation of the four species now known to occur in Japan.

All measurements in the text are given in millimeters. The adopted terms are mainly as in Carayon (1972) and Muraleedharan and Ananthakrishnan (1974). Depositories of the materials are abbreviated as follows: NIAES (National Institute of Agro-Environmental Sciences, Tsukuba); NSMT (Department of Zoology, National Science Museum, Tokyo); OPU (Entomological Laboratory, Osaka Prefecture University, Sakai). 


\section{Taxonomy}

Scoloposcelis albodecussata sp. nov.

(Figs 1, 4, 5, 8-15)

Diagnosis. Body elongate, parallel-sided, and shiny; inner half of clavus, basal half of corium and embolium, and inner basal area of membrane whitish brown, remainder of hemelytra dark brown; forefemur with row of spinules ventrally; mid- and hindfemora without spinules; paramere blade-like, weakly projecting at apex; copulatory tube almost membranous, bellows-like, broadened apically.

Description. Body (Fig. 1) generally blackish brown, elongate, shiny. Head (Figs 1,8) blackish brown, smooth on dorsal surface, shorter than width across eyes, sparsely covered with short pubescence; 2 pairs of long, erect setae present on sides of tylus and near inner anterior margins of eyes; vertex about twice as wide as eye in dorsal view; eyes reddish brown, prominent; ocelli reddish brown. Antennal segment I dark brown, stout, reaching to apex of head, covered with short pubescence at apex; segment II dark brown, much shorter than width of head across eyes, slightly thickened toward apex, covered with suberect pubescence shorter than width of segment II; segments III and IV brown, much shorter than segment II, covered with suberect pubescence of variable length; longest pubescence longer than 3 times width of each segment; segment IV weakly flattened, little longer than segment III; lengths of antennal segments I-IV ( $\delta / q) 0.13-0.14 / 0.14$ $0.15,0.34-0.36 / 0.37-0.39,0.25-0.26 / 0.25-0.28$, and $0.27-0.30 / 0.28-0.31$. Rostrum reaching middle of mesosternum, with very short pubescence; segment I to basal half of segment III blackish brown; apical half of segment III and segment IV yellowish brown; segment III about 2.4 times as long as segment II; segment IV about 0.6 times as long as segment III; lengths of rostral segments II-IV $(\delta / q) \quad 0.21-0.23 / 0.21-$ $0.26,0.51 / 0.55$, and $0.30-0.32 / 0.32-0.34$.

Pronotum (Figs 1, 8) blackish brown, trapezoidal, smooth but weakly depressed on posterior half, bearing long, erect setae at anterior $1 / 3$ of lateral mar-

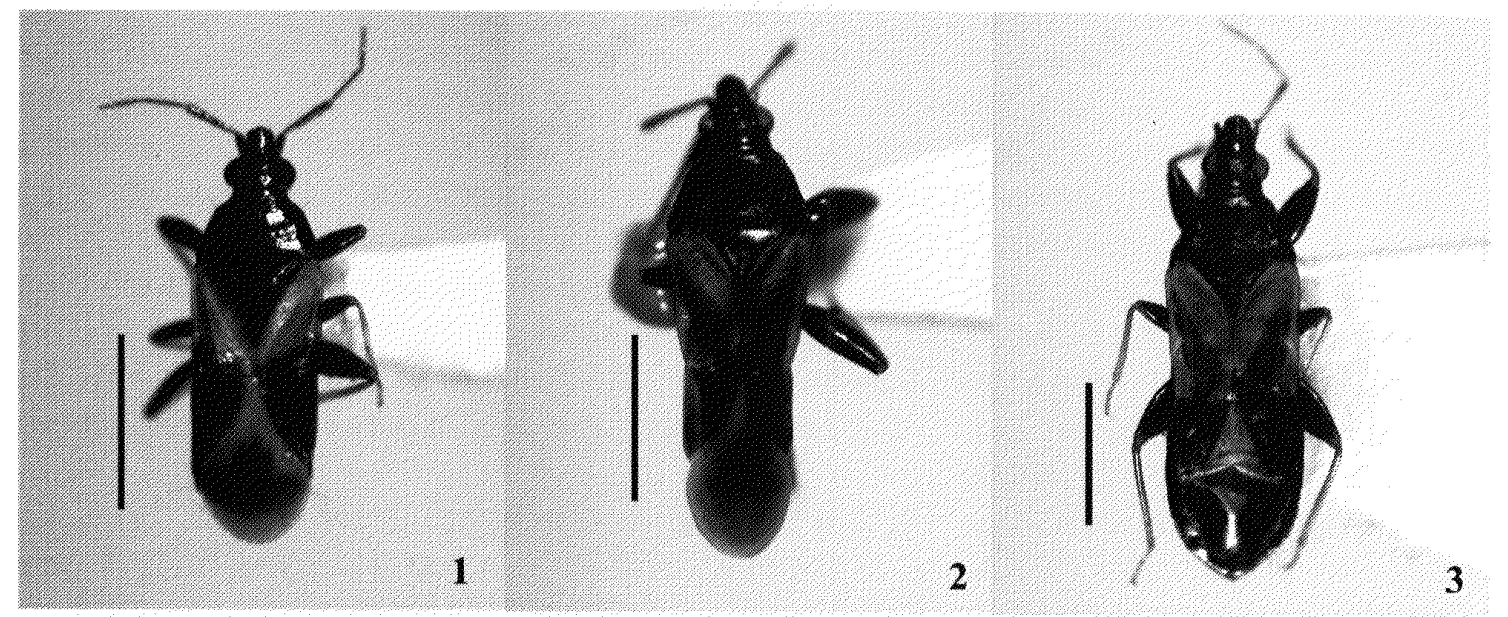

Figs 1-3. Japanese Scoloposcelis spp. 1, S. albodecussata sp. nov., holotype o from Maezato Dam, Ishigaki Is.; $2, S$. boninensis sp. nov., holotype ơ from Sekimonyama, Hahajima Is.; 3 , ditto, paratype + (NSMT-I-He 4693) from Mikazukiyama, Chichijima Is. Scale bars: $1.0 \mathrm{~mm}$. 

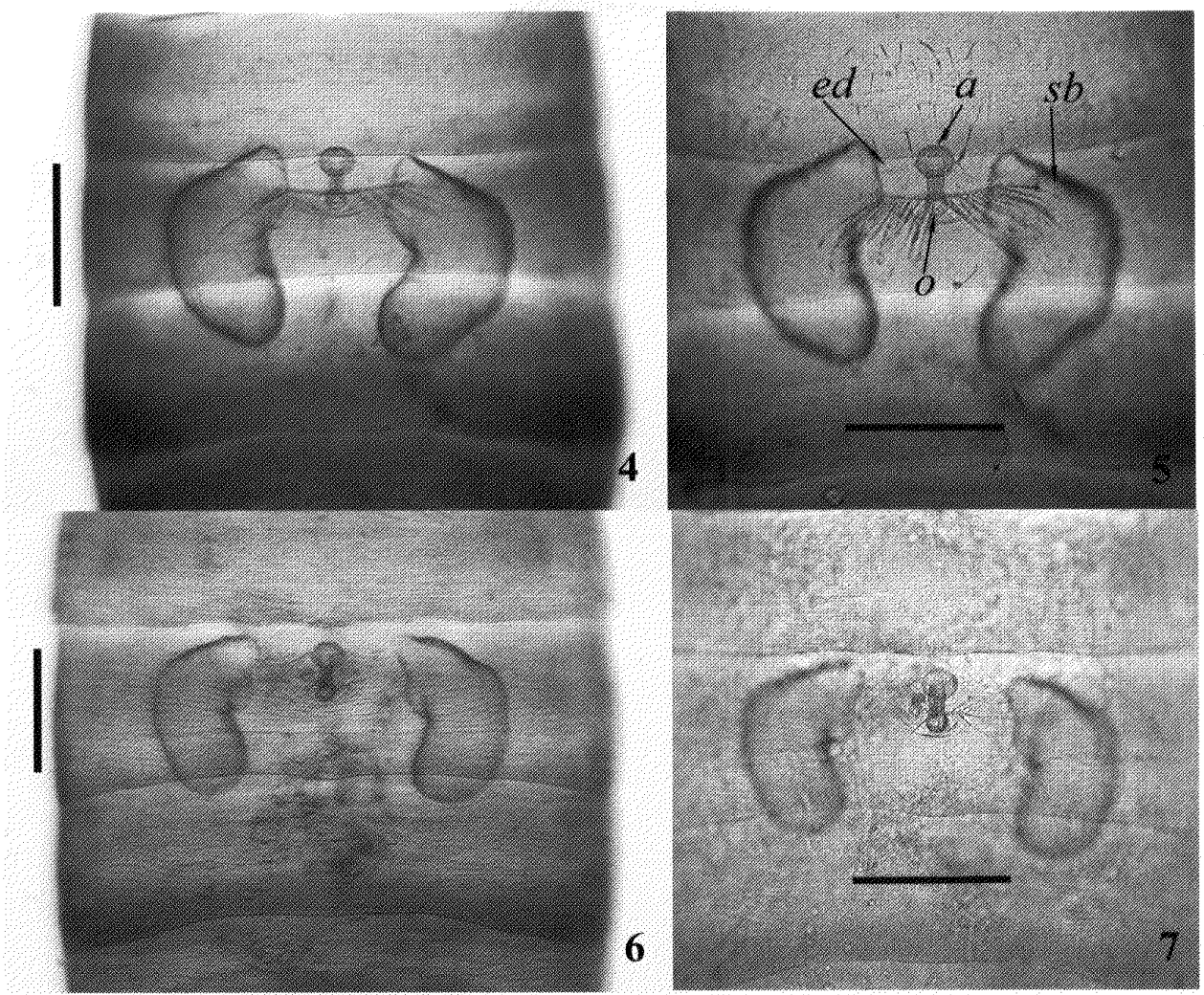

Figs 4-7. Uradenia of Scoloposcelis spp. seen from venter. 4, 5, S. albodecussata sp. nov., holotype; $6,7, S$. boninensis sp. nov., paratype of from Chichijima Is. Scale bars: $0.2 \mathrm{~mm}$. Abbreviations: a, ampulla; ed, efferent duct; 0 , orifice; sb, secretory body.

gins and on posterior angles; anterior margin slightly concave, about as long as mesal length; anterior half of lateral margin marginated and weakly rounded; collar indistinct, with short pubescence; posterior margin concave, more than twice as long as anterior margin. Scutellum blackish brown, smooth. Hemelytra parallelsided, sparsely covered with silky, golden pubescence; inner half of clavus, basal half of corium and embolium, and inner basal area of membrane whitish brown, remainder of hemelytra dark brown; cuneal lateral margin about 0.75 times as long as embolial margin; membrane with 1 or 2 veins. Ostiolar peritreme and evaporatorium (Fig. 9) reddish brown; ostiolar peritreme crescent, acute at apex, not reaching anterior margin of metapleuron. Legs (Figs 10-12) covered with short, silky pubescence; forefemur (Fig. 10) blackish brown, ventrally with row of 13-15 spinules of various size; foretibia dark brown at base, otherwise pale yellow; foretarsus pale yellow; mid- and hindfemora (Figs 11, 12) blackish brown, without spinules ventrally; mid- and hindtibiae and tarsi pale yellow except for dark brown midtibia.

Abdomen blackish brown, densely covered with short pubescence; scissures on abdominal tergite reaching end of posterior margin of segment III. Uradenia as shown in Figs 4, 5. Male genitalia as shown in Figs 13, 14; pygophore cup-shaped, covered with long setae posteroventrally; paramere blade-like, weakly projecting at apex, with very narrow groove running along its body. Female genitalia as 
shown in Fig. 15; copulatory tube almost membranous, curved, bellows-like, broadened apically.

Measurements ( $\delta /$ $/$ ). Body length 2.50-2.88/2.63-2.95; head length (excl. neck) $0.34-0.43 / 0.39-0.47$, width (incl. eyes) $0.43-0.47 / 0.48-0.49$; vertex width $0.21-0.24$ /
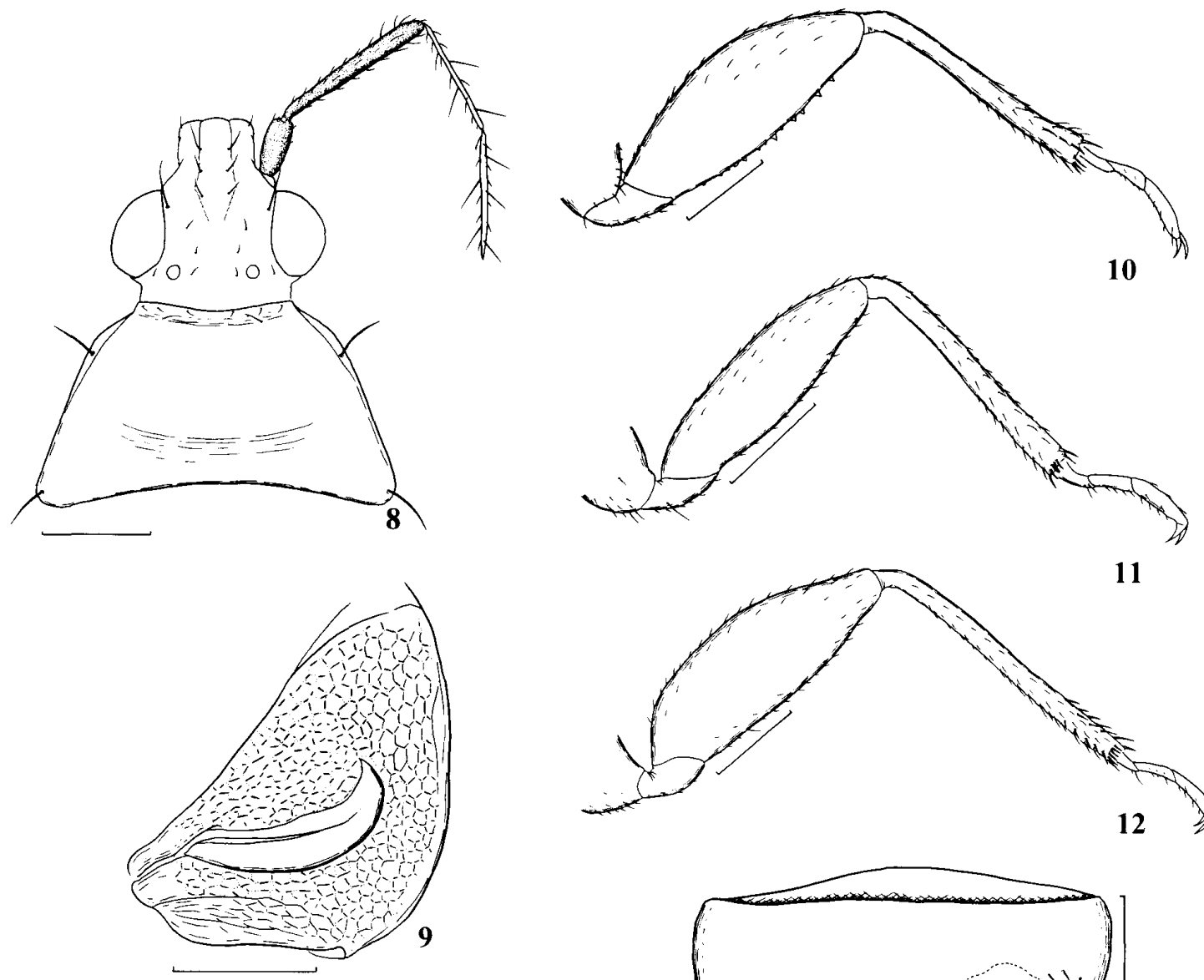

11
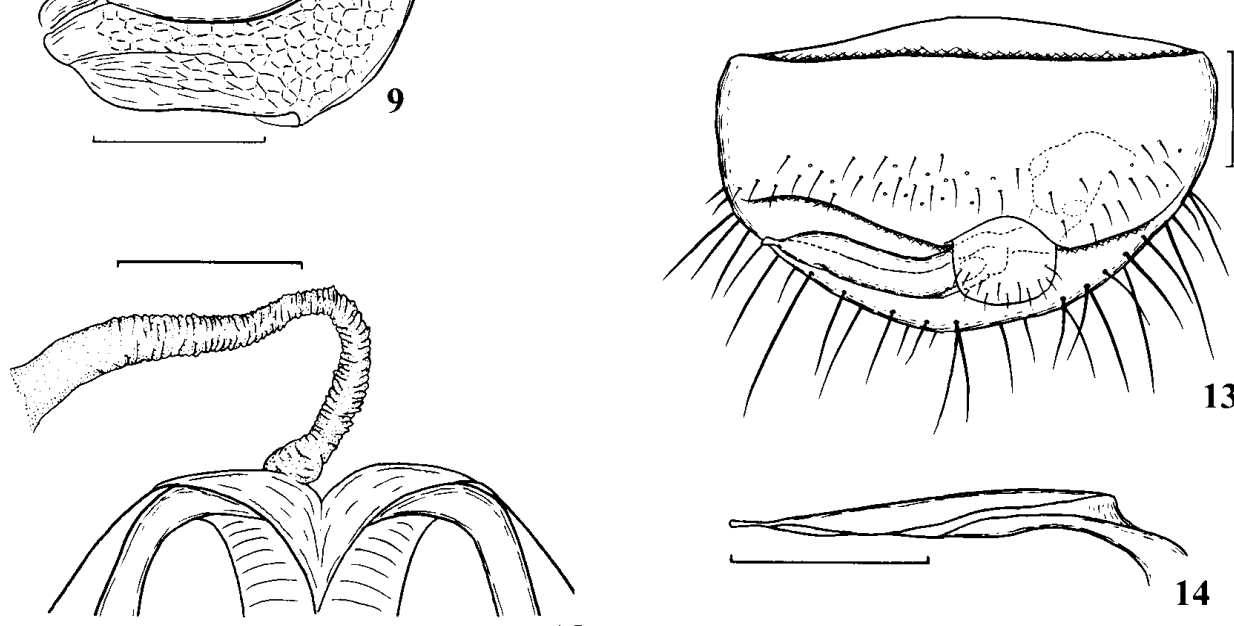

15

Figs 8-15. Scoloposcelis albodecussata sp. nov., holotype (8, 13, 14), and male (9-12) and female (15) paratypes from Ishigaki Is. 8, Head and pronotum, dorsal view; 9, ostiolar peritreme and evaporatrium, lateroventral view; 10, left foreleg, inner view; 11, left midleg, inner view; 12 , left hindleg, inner view; 13, pygophore (glass slide No. OPU-KY082), dorsal view; 14, paramere (glass slide No. OPU-KY082), posterior view; 15, copulatory tube, dorsal view. Scale bars: 0.2 $\mathrm{mm}$ for $8,10-12 ; 0.1 \mathrm{~mm}$ for $9,13-15$. 
$0.22-0.24$; distance between ocelli $0.13-0.15 / 0.15-0.16$; anterior pronotal width 0.34 $0.38 / 0.34-0.38$; mesal pronotal length $0.34-0.38 / 0.38$; basal pronotal width 0.75 $0.85 / 0.82-0.89$; length of embolial margin $0.65-0.80 / 0.70-0.80$; length of lateral cuneal margin $0.50-0.60 / 0.58-0.60$; maximum width across hemelytra $0.75-0.88 / 0.84-0.95$.

Type series. Holotype: $\delta$, "[Ryukyus] Maezato Dam, Ishigaki Is., Okinawa Pref., 17.v.2002, K. Yamada leg." (with glass slide No. OPU-KY082 for genitalia). Paratypes: [Okinawa Is.] 19, Hiji, Kunigami Vil., 4.X.2002, KY (K. Yamada); 2 , 29.X.2002, KY. [Ishigaki Is.] 1 , Urasoko forest road, 28.x.1998, K. Takahashi; $3 ₫ 4$, Fukaiomoto, 27.iv.2003, KY; $4 \$ 6$, Maezato Dam, 8.vi.2003, KY; $3 \delta^{\star}$ (one shown in Figs 9-12) 4 ㅇ (one shown in Fig. 15), same data as holotype; 19 , Omoto, 28.iv.2003, KY; 1 \%, Takeda forest road, 28.iv.2003, light trap, KY; 10 , Yoshihara, 20.iii.1998, K. Takahashi; 1 , Banna Park, 5.iv.2001, light trap, KY; $5 ð 1$, 31.iii.2002, KY; $1 \delta 1$, 16.v.2002, KY. [Iriomote Is.] $1 \delta 1 \%$, Shirahama, 27.v.2000, T. Ishikawa. The holotype and 42 paratypes are preserved at the OPU.

Distribution. Japan (the Ryukyus: Okinawa, Ishigaki, and Iriomote Islands).

Remarks. In general appearance this new species is similar to S. parallela and $S$. asiaticus. It can be distinguished from $S$. parallela by the vertex being about twice as wide as the eye in dorsal view (Fig. 8), the coloration of the hemelytra (Fig. 1), and the hindfemur lacking spinules on the ventral surface (Fig. 12), and from $S$. asiaticus by the head being shorter than the width across the eyes (Fig. 8), the rostrum reaching the middle of the mesosternum, and the mid- and hindfemora lacking spinules on the ventral surface (Figs 11, 12).

Biology. Many specimens, including all nymphal instars, were collected from under the bark of dead Castanopsis trees at several localities in the Ryukyus, mainly on Ishigaki and Iriomote Islands. On these islands, S. parallela is also known to occur (Yasunaga 2001). However, both species have not been collected simultaneously at the same localities. Adults of this new species were often attracted to light traps.

Etymology. From Latin albus (=white) combined with decussata (=decussate), referring to the distinctive white, decussate mark on the hemelytra; an adjective.

\section{Scoloposcelis boninensis $\mathrm{sp}$. nov.}

(Figs 2, 3, 6, 7, 16-23)

Diagnosis. Body elongate, parallel-sided; head and pronotum blackish brown, hemelytra chestnut brown with cuneus broadly darkened; femora spinulate ventrally; paramere digitiform, acute at apex; copulatory tube almost membranous, filiform, swollen like a balloon at apex.

Description. Body (Figs 2, 3) generally chestnut brown, elongate, weakly shiny. Head (Figs 2, 3, 16) blackish brown tinged with red, slightly roughened on dorsal surface, much longer than its width across eyes, sparsely covered with short pubescence; 2 pairs of long, erect setae present as in $S$. albodecussata; vertex about 2.5 times as wide as eye in dorsal view; eyes reddish brown, small; ocelli red. Antennal segment I blackish brown, stout, reaching nearly to apex of head, covered with short pubescence at apex; segment II yellowish brown, sometimes tinged with dark brown apically, about as long as width of head across eyes, slightly thickened toward apex, covered with suberect pubescence shorter than 
width of segment II; segments III and IV yellowish brown, much shorter than segment II, covered with suberect pubescence of variable length; longest pubescence longer than 3 times width of each segment; segment IV weakly flattened, little longer than segment III; lengths of antennal segments I-IV (o/ + ) $0.13 / 0.13$, $0.41 / 0.41, ? / 0.28-0.30$, and ?/0.29-0.31 (segments III and IV of male specimens miss-
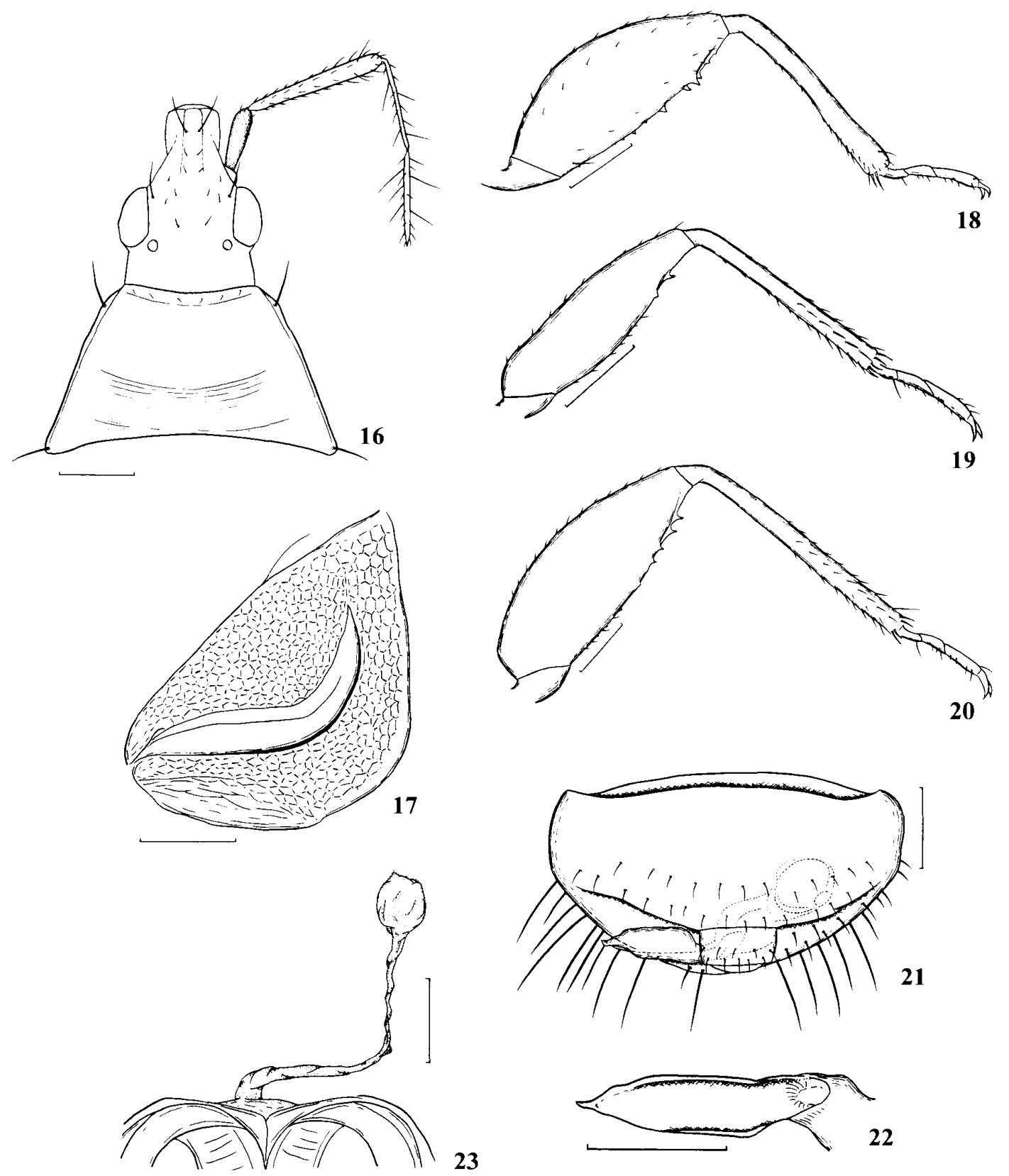

Figs 16-23. Scoloposcelis boninensis sp. nov., holotype $(17,21,22)$ and female paratypes (16, 18-20, 23) from Chichijima Is. 16, Head and pronotum, dorsal view; 17, ostiolar peritreme and evaporatorium, lateroventral view; 18, right foreleg, outer view; 19, right midleg, outer view; 20, right hindleg, outer view; 21, pygophore (glass slide No. OPU-KY095), dorsal view; 22, paramere (glass slide No. OPU-KY095), posterior view; 23, copulatory tube, dorsal view. Scale bars: $0.2 \mathrm{~mm}$ for $16,18-20 ; 0.1 \mathrm{~mm}$ for $17,21-23$. 
ing). Rostrum just reaching midcoxae, with very short pubescence; segment I to basal 3/4 of segment III dark brown, apical 1/4 of segment III and segment IV yellowish brown; segment III about 2.3 times as long as segment II; segment IV about 0.57 times as long as segment III; lengths of rostral segments II-IV ( $\delta / q) 0.26 / 0.26$, $0.60 / 0.60$, and $0.34 / 0.34$.

Pronotum (Figs 2, 3, 16) blackish brown, trapezoidal, slightly roughened on dorsal surface, weakly depressed on posterior half, bearing long, erect setae at anterior and posterior angles; anterior margin slightly concave, shorter than mesal length; lateral margin nearly straight, narrowly marginated; collar indistinct, with short pubescence; posterior margin concave, much more than twice as long as anterior margin. Scutellum blackish brown, slightly roughened. Hemelytra parallel-sided, sparsely covered with silky, golden pubescence; clavus, corium, and embolium chestnut brown; cuneus broadly darkened; cuneal lateral margin about 0.65 times as long as embolial margin; membrane smoky ocher, sometimes tinged with whitish brown at base, with 1 or 2 veins. Ostiolar peritreme and evaporatorium (Fig. 17) blackish brown, tinged with red; ostiolar peritreme curved anteriorly at middle, with acute apex, not reaching anterior margin of metapleuron. Legs (Figs 18-20) covered with short, silky pubescence; femora blackish brown, tibiae and tarsi yellowish brown; ventral surface of forefemur (Fig. 18) with row of 4 large and 6 to 8 small spinules located inside and 1 large spinule outside; midfemur (Fig. 19) with only 2 spinules ventrally, 1 of them located inside, the other outside and slightly more posteriorly; hindfemur (Fig. 20) with 2 series of spinules, inside series of them composed of 2 large and 3 to 4 small spinules, outside series composed of 2 large and 1 to 2 small spinules.

Abdomen blackish brown, densely covered with short pubescence; scissures on abdominal tergite reaching end of posterior margin of segment III. Uradenia as shown in Figs 6, 7. Male genitalia as shown in Figs 21, 22; pygophore cup-shaped, covered with long setae posteroventrally; paramere digitiform, acute at apex, with wide groove running along its body. Female genitalia as shown in Fig. 23; copulatory tube almost membranous, filiform, weakly twisted, swollen like a balloon at apex.

Measurements ( $\delta / q)$. Body length 2.88/2.88-3.13; head length (excl. neck) $0.47 / 0.47-0.48$, width (incl. eyes) $0.43 / 0.43-0.44$; vertex width $0.24 / 0.24-0.25$; distance between ocelli $0.17 / 0.17$; anterior pronotal width $0.38 / 0.38-0.39$; mesal pronotal length $0.43 / 0.43$; basal pronotal width $0.81 / 0.80-0.82$; length of embolial margin $0.75 / 0.80-0.90$; length of lateral cuneal margin $0.50 / 0.50-0.58$; maximum width across hemelytra $0.82 / 0.82-0.86$.

Type series. Holotype: $\delta$, "Sekimonyama, Hahajima Is., 3.viii.1996, T. Matsumoto" (with glass slide No. OPU-KY095 for genitalia) (OPU). Paratypes: [Chichijima Is.] 2 , Mikazukiyama, 10.vi.1976, T. Nakane (NSMT-I-He 4693 and 4694); 1 q (shown in Figs 16, 17), 28.vii.1996, T. Kishimoto (OPU); 19, Ômura, 1.X.1972, Y. Kusui (NIAES); 29 (one shown in Figs 18-20, 23), Yoakeyama, 30.v.1976, T. Nakane (NSMT-I-He 4695 and 4696); 2 , Fukurozawa, 11.vi.1976, T. Nakane (NSMT-I-He 4697 and 4698); 1 ' (shown in Figs 6, 7), "Chichijima, v.1970, Keizô Kojima, from tree litter [in Japanese]” (OPU); 1, 18.vi.1988, I. Matoba (without detailed locality) (OPU). [Hahajima Is.] 19, Higashiko, 6.vi.1976, T. Nakane (NSMT-I-He 4699).

Distribution. Japan (Ogasawara Islands).

Remarks. This new species is readily distinguished from its congeners by the 
chestnut brown hemelytra, each with a broadly darkened cuneus (Figs 2, 3) and from all but one species by the ventral spinulation of the femora (Figs 18-20). Judging from the description by Muraleedharan and Ananthakrishnan (1974), S. boninensis is similar to $S$. asiaticus in having spinulate femora, but besides the coloration of hemelytra, it can be easily separated from the latter by the length of the rostrum, which just reaches the midcoxae, and by the antennal segment II being tinged yellowish brown with dark brown apex (Fig. 3) and also being about as long as the width of the head across eyes (Fig. 16).

Biology. One male specimen (OPU) is labeled "from tree litter" in Japanese. No other biological information is available.

Etymology. Named after the type locality, the Bonin Islands; an adjective.

\section{Key to the Japanese species of Scoloposcelis}

1. Ventral surface of hindfemur spinulate. . .2

- Ventral surface of hindfemur not spinulate.

2. Antennal segments I and II dark brown, III and IV yellowish brown to brown; hemelytra blackish brown but pale brown basally; ventral surface of midfemur without spinules.

S. parallela

- Antennal segment I dark brown, II to IV yellowish brown; hemelytra chestnut brown with broadly darkened cuneus; ventral surface of midfemur with two spinules towards apex.

S. boninensis sp. nov.

3. Ventral surface of forefemur with row of spinules; paramere not spinulate

S. albodecussata sp. nov.

- Ventral surface of forefemur with two rows of spinules; paramere weakly spinulate in apical half. S. pulchella

\section{Acknowledgments}

We wish to express our cordial thanks to Dr. T. Yasunaga (JICA-SV, c/o Natural History Museum, Royal Tribhuvban University, Kathmandu, Nepal) and to Dr. M. Tomokuni (NSMT) for their valuable advice and critical comments on our study. We wish to thank the staff of the Yona Field, Subtropical Field Science Center, and the Iriomote Station, Tropical Biosphere Research Center, University of the Ryukyus, for providing facilities for our fieldwork. We are also indebted to the following entomologists for kindly providing materials: Dr. M. Tomokuni (NSMT), Dr. Y. Nakatani (NIAES), Dr. T. Ishikawa (Laboratory of Insect Resources, Tokyo University of Agriculture, Atsugi), and Mr. S. Nagashima (Eight Consultants Co., Okayama).

\section{References}

Carayon, J. 1954a. Deux genres nouveaux d'Hémiptères Anthocoridae du Brésil, représentant une tribu nouvelle. Bulletin du Muséum National d'Histoire Naturelle (2) 26: 596-601.

Carayon, J. 1954b. Un type nouveau d'appareil glandulaire propre aux mâles de certains Hémiptères Anthocoridae. Bulletin du Muséum National d'Histoire Naturelle (2) 26: 602606. 
Carayon, J. 1956. Anthocoridae Scolopini nouveaux d'Afrique tropicale (Hemipt. Heteropt.). Bulletin du Muséum National d'Histoire Naturelle (2) 28: 183-190.

Carayon, J. 1972. Caractères systématiques et classification des Anthocoridae (Hemipt.). Annales de la Société Entomologique de France (N. S.) 8: 309-349.

Herring, J. L. 1967. Heteroptera: Anthocoridae. Insects of Micronesia 7: 392-414.

Muraleedharan, N. and Ananthakrishnan, T. N. 1974. A new species of the genus Scoloposcelis Fieber (Heteroptera: Anthocoridae) from South India. Journal of Natural History 8: 511-512.

Péricart, J. 1996. Family Anthocoridae Fieber, 1836-flower bugs, minute pirate bugs. Pp. 108140. In: Aukema, B. and Rieger, C. (Eds) Catalogue of the Heteroptera of the Palaearctic Region. Volume 2. The Netherlands Entomological Society, Amsterdam.

Yasunaga, T. 2001. Family Anthocoridae Fieber, 1836 flower bugs, minute pirate bugs. Pp. 278-303, pls 85-89. In: Yasunaga, T., Takai, M. and Kawasawa, T. (Eds) A Field Guide to Japanese Bugs II-Terrestrial Heteropterans. Zenkoku Noson Kyoiku Kyokai, Tokyo. [In Japanese] 